\title{
Foreword
}

\section{Lisa Dempster}

IT Is A singular feeling to crack open the spine of a literary journal, open to a random page, and begin reading. It's especially exciting when the journal in question is a student publication, for the possibilities held within its covers are, I believe, enormous. Will I discover a new writer, be led to consider a fresh new perspective on the world, or learn something entirely new? So it was with a sense of happy anticipation that I dived into my explorations of Offset.

Student publications are incubators for new writers and experimental works, and create valuable publication opportunities for young and emerging writers. The pages of a student literary journal are supportive spaces for emerging writers to publish work, and as a result the writing within tends to be experimental and bold. Offset is no exception.

The contributors in this anthology represent a diversity of styles and genres, and the quality of writing is exceptional. Writing that is fresh, writing that is original-this is what makes Offset such a compelling collection of new literature.

Reading Offset, I was also filled with excitement about the innovative approach that the editorial team took when compiling the journal. Including a story in Arabic was a particularly bold move that must be singled out for praise. Not only does Arabic literature look beautiful on the page, but it speaks directly to the culture and community of Victoria University. In addition, teaming the printed publication with digital media and musical accompaniments is an excellent idea that explores the notion of what it is to create a literary journal, and makes a valuable 
companion to the printed word.

Altogether, Offset is an incredibly mature collection. It demonstrates that 'student' is not synonymous with 'amateur', and both its boldness and professional execution demands a wide audience.

As a former independent publisher, I understand the challenging and potentially arduous process that a team goes through to produce a journal like Offset. I appreciate that it is a long time in the making, and that each decision made along the way has culminated in the physical object that I, the lucky reader, get to hold in my hands.

It is therefore with genuine enthusiasm that I offer my congratulations to the Offset team on producing such a wonderful publication. The talent and imagination of the individuals involved in the creation of Offset is evident in all aspects of the journal, from design to editorial decisions. It is a remarkable book that I feel proud to have been a very small part of, and the Offset team should similarly feel very pleased with the amazing collection that they have published. I have no doubt that, should they choose it, excellent literary careers await each and every one of them.

Offset creates serious opportunities: chances for writers to be published, for readers to be inspired, and for students to gain hands-on experience in publishing. In its content it also makes a tangible and important contribution to Australia's literary culture. Why? Because within its pages are fresh new voices, the future thinkers and dreamers and doers of Australia.

The only feeling that comes close to cracking open the pages of a newly released literary journal is the satisfying experience of closing the cover after reading a well-executed, thoughtful publication. Offset is a journal that rewards its reader with both inspiration and contemplation. I have no doubt that anyone who finds their way to Offset volume 11 will be as delighted by the journal as I am.

Happy reading.

Lisa Dempster

Director, Emerging Writers' Festival 